\title{
ANALYSIS OF TEMPORAL AND SPATIAL PHYTOPLANKTON VARIABILITY IN A LONG ISLAND SALT MARSH
}

\author{
Russell A. Moll \\ Great Lakes Research Division. The University of Michigan, Ann Arbor, MI 48109, U.S.A. \\ and \\ F. JAMES ROHLF \\ Department of Ecology and Evolution, State University of New York, Stony Brook, NY 11794, U.S.A.
}

\begin{abstract}
A study of phytoplankton and related variables in a Long Island salt marsh was designed to incorporate three major sources of variation in the sampling regime: spatial, short-term temporal, and long-term temporal. The combination of multivariate (MANOVA and factor analysis) and univariate (ANOVA) data analyses was used to examine the relative importance of each source of variation in 11 variables and to aid in the ecological interpretation of the data. MANOVA confirmed that all three sources of variation were significant with temporal variation (weekly sampling and at different times of the day) more important than spatial variation (sampling at different stations). The analyses also indicated that sampling a dynamic, tidally-driven system, such as a small salt marsh, cannot be carried out on a once-per-day basis; tidal flushing and diurnal changes in primary production induce a large amount of variation into the concentrations of phytoplankton and related variables within the salt marsh.
\end{abstract}

\section{INTRODUCTION}

The measurement of species abundance and distribution is particularly difficult in aquatic areas where the fluid medium is non-stable (Hutchinson, 1961; Richerson et al., 1970). Subtle changes in water quality form distinct water masses which provide differentially suitable habitats for many aquatic organisms (Hall et al., 1970). A result of water mass formation is the non-random spatial distribution of plankton species commonly following a log or negative binomial function (Pielou, 1969, 1975).

The problem of studying the association of many organisms within a particular environment (or a niche-space) is compounded for planktonic species which may drift from one water mass to another; for example, an instantaneous "grab" sample can readily lead to false conclusions under these conditions (Margalef, 1969; Wiebe, 1970). A desirable environment occupied by a planktonic species could be where a high growth condition occurred rather than where the population was sampled. Just as spatial movement of organisms confounds defining a niche-space, so does temporal movement. Rapid species grazing or predation can reduce a large population to a small population with little apparent change in the physical environment (Steele, 1974). 
The large number of variables which influence species distribution and concentration demonstrates the need for intense sampling to reveal controlling mechanisms in the aquatic environment. Sampling must be conducted within a regime designed to evaluate both spatial and temporal variability. In addition to the intensity of sampling, the regime should be designed to adequately sample all major sources of variation which influence the distribution and density of organisms. Finally, a planned program of data analysis must be coupled with the field sampling to summarize the results in order that an ecological interpretation can be made. Although many intense field programs have been conducted, relatively few have had detailed data analysis (Platt et al., 1970; Platt \& Conover, 1971; Platt, 1975).

In 1972 and 1973 we designed and executed a field study of phytoplankton in a Long Island salt marsh. A major objective of the sampling regime was to reveal the importance of three major sources of variation: spatial (sampling three locations in a small marsh), short-term temporal (sampling from three to five times per day), and long-term temporal (sampling once per week for 16 months). Additionally, we were interested in the interaction of the phytoplankton and related variables with one another in the salt marsh ecosystem. To facilitate this study, 21 variables were measured at each station, all related to phytoplankton abundance and/or productivity. A description of the analytical techniques and the major results can be found in Moll (1977).

The purpose of this paper is to demonstrate the relative importance that different sources of variation may have in sampling planktonic populations in small. confined basins or coastal marshes. Although several techniques were available to carry out this analysis, we chose three commonly-used methods: MANOVA (multivariate analysis of variance), ANOVA (analysis of variance), and factor analysis.

\section{SAmpling Regime}

Samples were collected in Flax Pond, a 50-ha salt marsh on the north shore of Long Island, New York. Three sites were sampled (Fig. 1) from three to five times per day, once per week (almost always on Mondays) for 16 months (July 1972 to October 1973). In order to achieve a more balanced data set, only three time periods per day were considered in the statistical analyses. A total of 51 weekly sampling dates was available for the analyses; missing dates were a result of incomplete data sets or reduced sampling because of inclement weather. Twenty-one variables were measured, but only 11 variables were used in the analysis. These were: nitrate and nitrite nitrogen, chlorophyll $a$, yellow plant pigments in phytoplankton, water temperature, submarine light intensity, submarine light extinction coefficient, $\mathrm{pH}$, total dissolved $\mathrm{CO}_{2}$, phytoplankton concentration in cells/l, and Shannon-Wiener species diversity. The reduction in the data base from 21 to 11 variables was due to empty cells and non-independence in the excluded variables. 


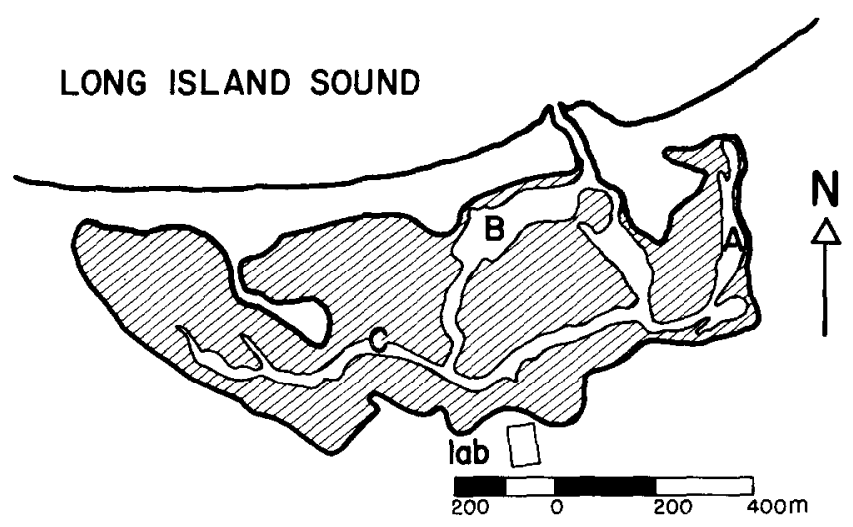

Fig. 1. The three sampling stations are shown in Flax Pond as A, B, and C: also shown on the map are Spartina flats (as shading) and the New York State Conservation Laboratory where samples were processed after collection.

\section{MULTIVARIATE ANALYSIS OF VARIANCE}

The data collection and analysis were structured to fit a three-way fixed main effect analysis with replication. The main effects tested were locations (sample sites), time of day, and weeks. The basic three-way fixed linear model was:

$$
Y_{i j k l}=\mu+\alpha_{i}+\beta_{i}+\gamma_{k}+(\alpha \beta)_{i j}+(\alpha \gamma)_{i k}+(\beta \gamma)_{j k}+(\alpha \beta \gamma)_{i j k}+\varepsilon_{i j k l},
$$

where: $\alpha=$ main effect due to sampling among weeks, $\beta=$ main effect due to sampling at different times within one day, $\gamma=$ main effect due to sampling different locations, $\alpha \beta=$ interaction among weeks and different times of day, $\alpha \gamma=$ interaction among weeks and sampling locations, $\beta \gamma$ - interaction among different times of day and sampling locations, $\alpha \beta \gamma=$ interaction among weeks, different times of day, and sampling locations. Replicate samples were collected at two of the three sample sites, thus the MANOVA was carried out with unequal but proportional sample sizes. The computations were based on an ANOVA technique in Sokal \& Rohlf (1969) and were modified to the multivariate mode. Tests of significance for the sums of squares and sums of products matrices were performed using the WilksLambda criterion (Morrison, 1967). Wilks-Lambda comparisons were made with the NT-SYS software package available from Rohlf et al. (1971).

The results of the MANOVA (Table I) show that all sources of variation, main effects and interactions, were significant at the $<0.001$ probability level. When interactions are significant, the main effects cannot be interpreted in isolation (Sokal \& Rohlf, 1969); thus, in order to state that a given main effect introduced significant variation, the other two main effects must be held constant. But, the results showed that the variance introduced by the main effects vastly outweighed the variance from the interactions. This conclusion was reached from three results: (1) plots of the individual sources of variation as exemplified in Fig. 2 showed the 


\section{TABLE I}

MANOVA Table: results of the multivariate analysis of variance with 11 phytoplankton related variables from Flax Pond salt marsh; $F$ statistics for the main effects of time of day and stations are exact, while all others approximate; all $F$ statistics were derived from the sums of squares matrices and have a probability of $<0.001$.

\begin{tabular}{|c|c|c|c|}
\hline Source of variation & d.f. & $F$ statistic ${ }^{*}$ & $\begin{array}{l}\text { Wilks-Lambda } \\
\text { criterion }\end{array}$ \\
\hline Weeks & $550 / 3220$ & $117.05^{* * *}$ & $6.089 \times 10^{-15}$ \\
\hline Time of day & $22 / 592$ & $428.38^{* * *}$ & $3.493 \times 10^{-3}$ \\
\hline Stations & $22 / 592$ & $41.75^{* * *}$ & $1.536 \times 10^{-1}$ \\
\hline $\begin{array}{l}\text { Interaction of weeks } \\
\text { and time of day }\end{array}$ & $1100 / 3278$ & $9.45^{* * *}$ & $1.649 \times 10^{-7}$ \\
\hline $\begin{array}{l}\text { Interaction of weeks } \\
\text { and stations }\end{array}$ & $1100 / 3278$ & $3.60 * * *$ & $1.737 \times 10^{-4}$ \\
\hline $\begin{array}{l}\text { Interaction of time } \\
\text { of day and stations }\end{array}$ & $44 / 1134$ & $17.00^{* * *}$ & $1.440 \times 10^{-1}$ \\
\hline $\begin{array}{l}\text { Interaction of weeks, } \\
\text { time of day, and stations }\end{array}$ & $2200 / 3294$ & $5.07 * * *$ & $8.871 \times 10^{-8}$ \\
\hline
\end{tabular}

* Program to calculate Wilks-Lambda criterion and $F$ ratios was provided as part of the NT-SYS multivariate package.

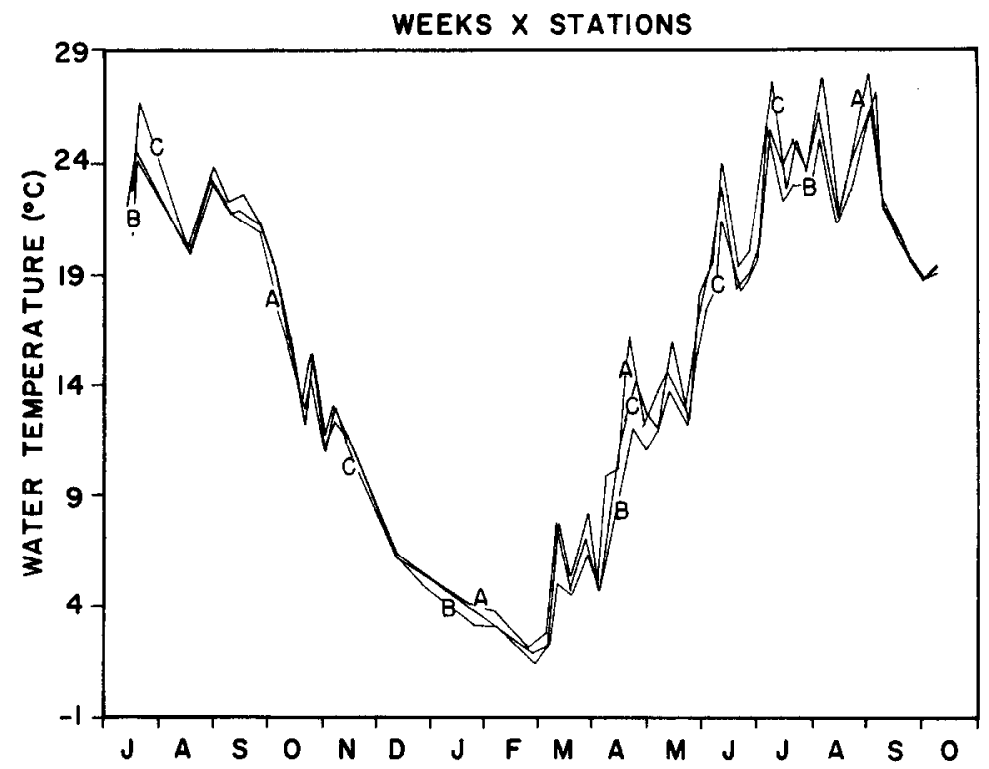

Fig. 2. Weekly means of water temperature $\left({ }^{\circ} \mathrm{C}\right)$ at the three sampling stations in the salt marsh: the graph shows the mean from each sampling station (as A, B, and C) throughout the 16-month sampling period from July 1972 to October 1973; the interaction between stations and weeks is shown by the crossing of the three lines; the main effect of weeks dominates the data as can be seen in the large change between weeks compared to the difference within one week. 
main effects dominating the variation in the data, (2) the approximate $F$ ratios were much higher for the main effects than the interaction, and (3) almost any source of variation greater than the error variation would be significant with such a large number of degrees of freedom, as was the case with the interaction sources.

The first result, the plots of variation, was the most conclusive. The example in Fig. 2 shows the variation in water temperature across weeks and between sample stations. The graph has three lines marked A, B, and C (for each station) running across the 16-month sampling period. The extent to which the three lines are not parallel is a measure of the degree of interaction between main effects - weeks and stations. The extent to which the slope of the three curves deviates from a horizontal line is a measure of the main effect of weeks. The graph shows that even though interaction is present, the main effect dominates the analysis. Similar graphs for the other variables and with other main effects produced comparable results.

The MANOVA showed that the effect of sampling across different weeks, at different times of the day, and at closely spaced stations were significant. The total variation relative to the error variance was greater for the time-of-day and weeks effects compared to the stations effects (Table I). Ecologically this result implied that the temporal changes in the environment induced the largest changes in phytoplankton and related variables considered collectively. This implication was investigated further with additional techniques.

\section{ANALYSIS OF VARIANCE}

Although the MANOVA could be considered a complete analysis by itself, compilation of individual ANOVA tables allowed a comparison of the overall MANOVA results to any one variable. Compilation of an ANOVA table for any one variable was a simple matter once the MANOVA was complete. Each sum of squares required to make the ANOVA table was found in the diagonal of the appropriate matrix of the MANOVA. The sums-of-products and sums-of-squares matrices derived in the MANOVA were variance-covariance matrices, with sums of squares found along the diagonal.

The individual ANOVAs were not totally independent of the MANOVA results. The dependencies among the 11 variables produced the same results for some of the ANOVAs as the MANOVA. Yet, there was enough independence among the variables that many differences were observed between the ANOVAs and the MANOVA. The ANOVA tables are shown in Table II. Five variables (nitritenitrogen, water temperature, submarine light intensity, extinction coefficient, and $\mathrm{pH})$ showed the same results as was found in the multivariate mode - all sources of variation were significant. The analysis of total $\mathrm{CO}_{2}$, chlorophyll $a$, and pheopigment data showed all main effects were significant, but one or more interactions were non-significant. Samples at different limes of the day did not have a significant effect on nitrate-nitrogen, total phytoplankton cells/l, and species diversity 
TABLE II

ANOVA Tables: individual analysis of variance tables for the 11 phytoplankton related variables; sums of squares for each ANOVA were calculated as part of the MANOVA.

\begin{tabular}{|c|c|c|c|c|c|c|c|c|}
\hline Source & SS & d.f. & MS & $F$-ratio & SS & d.f. & MS & $F$-ratio \\
\hline \multicolumn{5}{|c|}{ Nitrate nitrogen (N-NO.3) } & \multicolumn{4}{|c|}{ Nitrite nitrogen ( $\left.\mathrm{N}-\mathrm{NO}_{2}\right)$} \\
\hline W & 229446 & 50 & 4589 & $7.81 * * *$ & 14710 & 50 & 294 & $1547^{* * *}$ \\
\hline$T$ & 2372 & 2 & 1186 & $2.02 \mathrm{~ns}$ & 4.4 & 2 & 2.2 & $11.60^{* * *}$ \\
\hline$S$ & $4646 ?$ & $?$ & 23231 & $39.51 * * *$ & 6.6 & 2 & 3.3 & $17.13^{* * *}$ \\
\hline $\mathrm{W} \times \mathrm{T}$ & 77203 & 100 & 772 & $1.31 \mathrm{~ns}$ & 608 & 100 & 6.1 & $31.78 * * *$ \\
\hline$W \times S$ & 91732 & 100 & 917 & $1.56^{*}$ & 82 & 100 & .82 & $4.32^{* * *}$ \\
\hline $\mathrm{T} \times \mathrm{S}$ & 2999 & 4 & 749 & $1.26 \mathrm{~ns}$ & 3.8 & - 4 & .95 & $4.97^{* * *}$ \\
\hline 3 way & 302199 & 200 & 1512 & $2.57 * * *$ & 190 & 200 & .95 & $4.98 * * *$ \\
\hline \multirow[t]{2}{*}{ Error } & 179912 & 306 & 587 & & 58 & 306 & .19 & \\
\hline & \multicolumn{4}{|c|}{ Chlorophyll $a$} & \multicolumn{4}{|c|}{ Water temperature } \\
\hline W & 15723 & 50 & 314 & $18.47^{* * *}$ & 39166 & 50 & 783 & $5616^{* * *}$ \\
\hline $\mathrm{T}$ & 190 & 2 & 95 & $5.59^{* * *}$ & 238 & 2 & 119 & $856^{* * *}$ \\
\hline$S$ & 631 & 2 & 316 & $18.55^{* * *}$ & 86 & 2 & 43 & $307 * * *$ \\
\hline$W \times T$ & 2049 & 100 & 21 & $1.20 \mathrm{~ns}$ & 484 & 100 & 4.8 & $34.7 * * *$ \\
\hline$W \times S$ & 1640 & 100 & 16 & $.96 \mathrm{~ns}$ & 194 & 100 & 1.9 & $13.9^{* * *}$ \\
\hline$T \times S$ & 249 & 4 & 62 & $3.66 * *$ & 15 & 4 & 3.7 & $26.4^{* * *}$ \\
\hline 3-way & 8897 & 200 & 44 & $2.61 * * *$ & 217 & 200 & 1.1 & $7.8 * * *$ \\
\hline Error & 5211 & 306 & 17 & & 43 & 306 & 0.1 & \\
\hline
\end{tabular}

Submarine light intensity

$\begin{array}{crrl}\mathrm{W} & 97.97 & 50 & 1.96 \\ \mathrm{~T} & 3.32 & 2 & 1.66 \\ \mathrm{~S} & 0.03 & 2 & 0.02 \\ \mathrm{~W} \times \mathrm{T} & 17.16 & 100 & 0.17 \\ \mathrm{~W} \times \mathrm{S} & 1.17 & 100 & 0.01 \\ \mathrm{~T} \times \mathrm{S} & 0.48 & 4 & 0.12 \\ \text { 3-way } & 3.81 & 200 & 0.02 \\ \text { Error } & 0.17 & 306 & 0.0006\end{array}$

Extinction coefficient

$\begin{array}{crrr}\mathrm{W} & 49.52 & 50 & 0.99 \\ \mathrm{~T} & 10.39 & 2 & 5.19 \\ \mathrm{~S} & 94.09 & 2 & 47.05 \\ \mathrm{~W} \times \mathrm{T} & 8722 & 100 & 087 \\ \mathrm{~W} \times \mathrm{S} & 32.28 & 100 & 0.32 \\ \mathrm{~T} \times \mathrm{S} & 3.63 & 4 & 0.91 \\ \text { 3-way } & 143.87 & 200 & 0.72 \\ \text { Error } & 65.62 & 306 & 0.21\end{array}$

Dissolved carbon dioxide

$\begin{array}{ccrcc}\mathrm{W} & 4949 & 50 & 98.9 & 134 * * * \\ \mathrm{~T} & 48 & 2 & 24.2 & 32.8^{* * *} \\ \mathrm{~S} & 30 & 2 & 14.9 & 20.1 * * * \\ \mathrm{~W} \times \mathrm{T} & 665 & 100 & 6.6 & 9.0^{* * *} \\ \mathrm{~W} \times \mathrm{S} & 139 & 100 & 1.4 & 1.9 * * \\ \mathrm{~T} \times \mathrm{S} & 6.0 & 4 & 1.5 & 2.0 \mathrm{~ns} \\ \text { 3-way } & 466 & 200 & 2.3 & 3.2 * * * \\ \text { Error } & 226 & 306 & 0.74 & \end{array}$

Phytoplankton species diversity

\begin{tabular}{crrrc}
$\mathrm{W}$ & \multicolumn{1}{c}{176} & 50 & 3.52 & $46.9^{* * *}$ \\
$\mathrm{~T}$ & 0.09 & 2 & 0.04 & $0.57 \mathrm{~ns}$ \\
$\mathrm{~S}$ & 1.54 & 2 & 0.77 & $10.3^{* * *}$ \\
$\mathrm{~W} \times \mathrm{T}$ & 21.77 & 100 & 0.22 & $2.90^{* * *}$ \\
$\mathrm{~W} \times \mathrm{S}$ & 20.05 & 100 & 0.20 & $2.67 * * *$ \\
$\mathrm{~T} \times \mathrm{S}$ & 0.73 & 4 & 0.18 & $2.41 \mathrm{~ns}$ \\
3-way & 51.26 & 200 & 0.26 & $3.41 * * *$ \\
Error & 22.98 & 306 & 0.08 &
\end{tabular}

Sources of variation: $\mathrm{W}$, among weeks; $\mathrm{T}$, among times of day; $\mathrm{S}$, among sample sites; Error, replicate variance. Levels of significance: ${ }^{* * *}, P=0.001 ;{ }^{* *}, P=0.01 ; *, P=0.05 ;$ ns, non-significant. 
(Table II). Additionally, samples at different sample sites did not differ significantly in total cells/1.

Similar to the MANOVA procedure, we considered only the main effects as major sources of variation in the data (based on the same reasoning as was used for the MANOVA). Twenty-nine of the 33 main effect sources of variation ( 3 effects $\times 11$ variables) were significant, all at the $<0.001$ probability level. This high number of significant main effects could be attributed to several factors, including: a low replicate error variance producing high $F$ ratios, the high number of degrees of freedom, and the high level of variance introduced into the data by the main effects. Irrespective of the cause of the large proportion of significant treatment effects, these results show that both on a univariate and multivariate basis, temporal and spatial variation must be considered in salt marsh experimental designs.

Some confounding of the time-of-day and stations effects may have occurred. Sampling was conducted by one person (R.A.M.), thus the three sample sites were not visited simultaneously, but rather within $\approx 30 \mathrm{~min}$ of one another. A strong influence of time of day (which was evident from the MANOVA) could contribute to the among-station variance because of non-simultaneous sampling.

Three of the four non-significant main effects observed in the ANOVAs (Table II) were from the time-of-day source. All three variables, nitrate-nitrogen, total cells $/ 1$, and species diversity, appeared to change on a slow temporal scale. But, the nonsignificant effect of time of day on phytoplankton concentrations and diversity may have been due to considerable variability in replicate phytoplankton cell counts. The non-significant effect of sampling sites on total cells/1 was likely caused by the same problem, high error variance.

\section{FACTOR ANALYSIS}

The sums-of-squares and sums-of-products matrices were readily converted to correlation matrices by the simple transformation:

$$
C_{i j}=S P_{i i} / \sqrt{S P_{i i} \times S P_{i j}},
$$

where: $C_{i j}$ is the $i$ th row and $j$ th column element of the new correlation matrix $C$, and $S P$ is the original sums-of-products matrix. These newly formed matrices contain the correlations between variables with all but one source of variation held constant. We could then examine correlations between all variables with only the variance among weeks influencing the data, and likewise for among stations or time of day. The interaction sums-of-squares matrices were also transformed to correlation matrices, but we found the interpretation of these matrices difficult, and have not presented the results below.

Factor analysis was used as an aid in interpreting the three main effects correlation matrices. The factor technique used was the iterative Minres technique (Harman, 1967). Convergence of communalities was deemed sufficient when 
succeeding estimates differed by $<10^{-5}$ or after 20 iterations. The factor matrices were obliquely rotated using the primary product function-plane method of Katz \& Rohlf (1974).

TABLE III

Factor analysis on weeks correlation matrix: oblique primary pattern solution; correlations between oblique factors $1: 2-0.083,1: 3-0.343,2: 30.048$.

\begin{tabular}{lrrrr}
\hline & \multicolumn{3}{c}{ Factor loadings } \\
\cline { 2 - 4 } \multicolumn{1}{c}{ Variable } & \multicolumn{1}{c}{ Factor : 1} & \multicolumn{1}{c}{2} & \\
\cline { 2 - 4 } \multicolumn{1}{c}{ Sums of squares: } & 2.974 & 2.285 & 0.896 & Communality \\
\hline Nitrate-nitrogen & 0.035 & -0.795 & 0.026 & 0.636 \\
Nitrite-nitrogen & 0.236 & -0.546 & -0.101 & 0.406 \\
Chlorophyll $a$ & -1.000 & -0.036 & 0.043 & 1.000 \\
Plant pigments & -0.911 & 0.035 & -0.046 & 0.810 \\
Water temperature & 0.050 & 0.748 & -0.518 & 0.805 \\
Submarine light & 0.013 & 0.568 & 0.205 & 0.373 \\
Ext. coefficient & -0.252 & -0.036 & -0.018 & 0.060 \\
pH & -0.024 & 0.001 & 0.793 & 0.643 \\
Dissolved CO ${ }_{2}$ & -0.070 & 0.504 & -0.479 & 0.448 \\
Total cells $/ 1$ & -0.581 & 0.124 & 0.310 & 0.588 \\
Species diversity & 0.025 & 0.137 & -0.568 & 0.344 \\
\hline
\end{tabular}

The correlation matrix and subsequent factor analysis on the althong-weeks correlations yielded three factors (Table III). The first and most important factor has high loadings for phytoplankton biomass, e.g. chlorophyll $a$, pheo-pigments, and total cells $/ 1$. The second factor has high loadings for water temperature, light intensity, $\mathrm{CO}_{2}$, and dissolved nitrogen. The third factor has high loadings for $\mathrm{pH}$, species diversity, $\mathrm{CO}_{2}$, and water temperature.

The time-of-day sums-of-products matrix yielded many high correlations upon transformation. Factor analysis does a particularly poor job of analyzing correlation matrices where many of the correlations are large. Only two factors were extracted from the time-of-day correlation matrix (Table IV), those variables which changed noticeably during the day (first factor), and those which did not (second factor). The poor separation was evident as submarine light (which changes rapidly during the day) had high loadings on the second factor with $\mathrm{NO}_{3}$, while total cells/l (which that $A$ NOVA showed did not change during the day) did not.

The third factor analysis using the among-stations correlation matrix suffers the same problem as the time-of-day analysis; most of the correlations are large. The two-factor solution from the among-stations correlation matrix (Table V) shows relatively poor separation of variables. Total phytoplankton cells/l had high loadings on both factors despite this being the only variable which had a nonsignificant main effect from sampling among stations. 
TABLE IV

Factor analysis on time of day correlation matrix : oblique primary pattern solution; correlations between oblique factors -0.180 .

\begin{tabular}{|c|c|c|c|c|}
\hline \multirow[b]{3}{*}{ Variable } & \multicolumn{3}{|c|}{ Factor loadings } & \multirow[b]{3}{*}{ Communality* } \\
\hline & Factor: & 1 & 2 & \\
\hline & Sums of squares: & 8.739 & 2.261 & \\
\hline Nitrate-nitrogen & & 0.012 & -0.998 & 1.000 \\
\hline Nitrite-nitrogen & & 0.981 & -0.084 & 1.000 \\
\hline Chlorophyll $a$ & & -1.000 & -0.038 & 1.000 \\
\hline Plant pigments & & -0.995 & 0.027 & 1.000 \\
\hline Water temperature & & 1.000 & 0.073 & 1.000 \\
\hline Submarine light & & -0.038 & -1.000 & 1.000 \\
\hline Ext. coefficient & & -1.000 & -0.130 & 1.000 \\
\hline $\mathrm{pH}$ & & 0.998 & 0.370 & 1.000 \\
\hline Dissolved $\mathrm{CO}_{2}$ & & -0.985 & -0.425 & 1.000 \\
\hline Total cells/1 & & -1.000 & -0.143 & 1.000 \\
\hline Species diversity & & 0.978 & -0.098 & 1.000 \\
\hline
\end{tabular}

* Because there were only three time periods sampled there were only 2 d.f., and thus only two dimensions to the data; therefore, $h^{2}=1.000$ when $k=2$.

TABLE V

Factor analysis on stations correlation matrix: oblique primary pattern solution; correlations between oblique factors -0.364 .

\begin{tabular}{|c|c|c|c|c|}
\hline \multirow[b]{3}{*}{ Variable } & \multicolumn{3}{|c|}{ Factor loadings } & \multirow[b]{3}{*}{ Communality* } \\
\hline & Factor: & 1 & 2 & \\
\hline & Sums of squares: & 7.79 & 3.21 & \\
\hline Nitrate-nitrogen & & 0.021 & -0.992 & 1.000 \\
\hline Nitrite-nitrogen & & -1.000 & -0.448 & 1.000 \\
\hline Chlorophyll $a$ & & 0.511 & -0.693 & 1.000 \\
\hline Plant pigments & & 0.614 & -0.597 & 1.000 \\
\hline Water temperature & & 1.000 & 0.049 & 1.000 \\
\hline Submarine light & & 0.164 & 1.000 & 1.000 \\
\hline Ext. coefficient & & 0.969 & -0.077 & 1.000 \\
\hline $\mathrm{pH}$ & & -0.805 & 0.369 & 1.000 \\
\hline Dissolved $\mathrm{CO}_{2}$ & & 0.805 & -0.369 & 1.000 \\
\hline Total cells/1 & & -0.632 & -1.000 & 1.000 \\
\hline Species diversity & & 0.328 & -0.833 & 1.000 \\
\hline
\end{tabular}

* Because there were only three stations sampled there were only 2 d.f., and thus only two dimensions to the data; therefore, $h^{2}=1.000$ when $k=2$. 


\section{DISCUSSION}

The separation and quantification of the different sources of variation in the phytoplankton data showed that in the Flax Pond salt marsh the variation in phytoplankton concentrations and associated variables was greatest among weeks. Diurnal variation was somewhat less than among weeks, and among-station variation was smaller than among weeks. The significant changes in 2-b time periods in a suite of variables for a tidally driven system as Flax Pond have important implications for sampling programs in salt marshes. Larger bodies of water have more stability and their temporal variation is on a slower time scale (Platt, 1975). The results of the MANOVA implied that sampling in a dynamic system, as a salt marsh, cannot be carried out on a once-per-day basis without considering the time-of-day variation. Sampling at different locations within a salt marsh is not as important as sampling on a carcfully planned temporal regime.

The analysis of each variable separately with ANOVA somewhat broadened our understanding of the salt marsh. The ANOVA for total phytoplankton with two non-significant main effects yielded the largest contrast to the MANOVA. This result indicated that although phytoplankton concentrations were not changing between stations and throughout the day, many related variables were changing; phytoplankton niche-space definition is very difficult under these conditions. Phytoplankton species diversity and $\mathrm{NO}_{3}-\mathrm{N}$ were not affected by time of day in contrast to the MANOVA results. Similar to the total phytoplankton cells/l, species diversity would be expected to change relatively slowly, yielding a non-significant effect for time of day and stations. Yet, the effect of sampling at different stations was significant for species diversity. A closer examination of the total phytoplankton cells ANOVA table showed a high error variance; the high error variance could have originated either from high variability between replicate samples, or high sample processing variability.

The factor analyses yielded insights into the data when the three different treatments were isolated. The three-factor solution of the among-weeks correlation matrix revealed that several variables which are usually closely coupled in the nearshore marine environment responded differently in Flax Pond salt marsh. The normal limiting nutrient of $\mathrm{NO}_{3}-\mathrm{N}$ (Ryther \& Dunstan, 1971) was not found on the same factor as phytoplankton biomass. Evidently a common factor was not influencing both $\mathrm{NO}_{3}-\mathrm{N}$ levels and plankton biomass. Phytoplankton could have shifted to $\mathrm{NH}_{3}-\mathrm{N}$ as a nitrogen source in that Whitney et al. (1975) observed very high $\mathrm{NH}_{3}-\mathrm{N}$ concentrations in Flax Pond. Nitrogen levels appeared to vary more as a function of fixation within the marsh (Whitney et al., 1975) than as a consequence of phytoplankton utilization. Phytoplankton biomass (cells/1 and chlorophyll) and primary production related variables $\left(\mathrm{CO}_{2}, \mathrm{pH}\right)$ also did not vary together across weeks, an indication of the slow but noticeable shift in assimilation ratio throughout the year; this shift was observed when the in situ ${ }^{14} \mathrm{C}$ results were compared to the chlorophyll $a$ data (Moll, 1977). 
The factor analysis from the time-of-day data separated the data into two factors; those variables which change considerably with time of day, and those variables which did not. Evidently a small tidal basin has a high level of short-term temporal variation, which is not a surprising conclusion. Yet, relatively few studies appear to recognize this conclusion when they set up a sampling program. Tidal mixing was most likely the major cause of the short-term temporal variability as has been reported in other salt marshes and small tidal basins (Nixon \& Oviatt, 1973; Platt, 1975).

The results of the factor analysis of the among-stations correlation matrix do not lend themselves to an easy interpretation. Initially the two factors appeared to represent those variables which change considerably among stations, and those variables that do not change. But, upon further scrutiny, the results of the factor analysis were not clear-cut, despite the significant variation observed in the station's main effect in both the MANOVA and ANOVA analyses. Several conclusions are possible from results of the factor analysis among stations: the spatial variability in the salt marsh was very much under-sampled with only three stations. $\Lambda$ lthough the three stations did identify significant spatial variability, there were insufficient data available to further characterize trends in individual variables among stations. Another conclusion is that some confounding due to short-term temporal variation is present in the among-stations variance. This confounding is due to the sampling program. The stations were sampled sequentially rather than simultancously, and very often in the same order $-\mathrm{A} \rightarrow \mathrm{B} \rightarrow \mathrm{C}$. The conclusion from this study is that spatial variability in even a small salt marsh like Flax Pond should be considered in any sampling program, but not at the expense of neglecting short-term temporal variation.

The separation and analysis of the different sources of variance emphasized the dynamic nature of Flax Pond salt marsh. The large changes observed in most phytoplankton-related variables between tidal cycles were not surprising considering previous research (Nixon \& Oviatt, 1973). But, the significant variation observed in samples taken only $2 \mathrm{~h}$ apart underscores the high metabolic activity of the marsh ecosystem; evidently the 12-h tidal cycle can account for only a part of the dynamic state of the salt marsh. Diurnal variation induced, in part, by daily photosynthesis must also play a large role in marsh ecology. As a result of the constantly changing conditions of phytoplankton parameters in the salt marsh, defining phytoplankton niche-space becomes a difficult exercise. This research shows that phytoplankton can be an important component of the salt marsh ecosystem, but their presence should be viewed as transient.

\section{ACKNOWLEDGEMENTS}

This research was conducted at Brookhaven National Laboratory and S.U.N.Y. at Stony Brook, supported by U.S. Atomic Energy Commission and the National 
Science Foundation under grant No. AG-375. Contribution No. 271 of the Great Lakes Research Division, University of Michigan.

Considerable thanks go to Drs. P. Moll and P. Smouse, Department of Human Genetics, University of Michigan, and Dr. W. Chang, Great Lakes Research Division, for reviewing the manuscript and offering many helpful suggestions.

\section{REFERENCES}

Hall, D.J., W.E. CoOper \& E. E. Werner, 1970. An experimental approach to the production dynamics and structure of freshwater animal communities. Limnol. Oceanogr., Vol. 15, pp. 839-928.

HaRman, H. H., 1967. Modern factor analysis. University of Chicago Press, $469 \mathrm{pp}$.

Hutchinson, G. E., 1961. The paradox of the plankton. Am. Nat., Vol. 95, pp. 137-146.

KaTZ, J.O. \& F.J. RoHLF, 1974. Functionplane - a new approach to simple structure rotation. Psychometrika, Vol. 39, pp. 37-51.

MARGalef, R., 1969. Diversity and stability: a practical proposal and a model of interdependence. In, Diversity and stability in ecological systems, edited by G. M. Woodwell and H. H. Smith, Brookhaven Symposium, No. 22, pp. 25-37.

MoLL, R.A., 1977. Phytoplankton in a temperate zone salt marsh: net production and exchanges with coastal waters. Mar. Biol., Vol. 42, pp. 109-118.

Morrison, D. F., 1967. Multivariate statistical methods. McGraw-Hill, Inc., New York, 338 pp.

Nixon, S. \& C. Oviatt, 1973. Ecology of a New England salt marsh. Ecol. Monogr., Vol. 43, pp. 463-498.

PIElou, E. C., 1969. An introduction to mathematical ecology. Wiley Interscience, New York, $286 \mathrm{pp}$.

Pielou, E. C., 1975. Ecological diversity. Wiley Interscience, New York, 165 pp.

PLATT, T., 1975. Analysis of the importance of spatial and temporal heterogeneity in the estimation of annual production by phytoplankton in a small enriched marine basin. J. exp. mar. Biol. Ecol., Vol. 18, pp. 99-109.

PLATT, T. \& R. Conover, 1971. Variability and its effect on the $24 \mathrm{~h}$ chlorophyll budget of a small marine basin. Mar. Biol., Vol. 10, pp. 52-65.

Platt, T., L. Dickie \& R.W. TRITES, 1970. Spatial heterogeneity of phytoplankton in a near-shore environment. J. Fish. Res. Bd Can., Vol. 27, pp. 1453-1473.

Richerson, P., R. Armstrono \& C. R. Goldman, 1970. Contemporancous discquilibrium, a new hypothesis to explain the "paradox of the plankton". Proc. Natn. Acad. Sci., Vol. 67, pp. 1710-1714.

Rohlf, F. J., J. KIShPaugh \& D. KIRK, 1971. NT-SYS, Numerical Taxonomy System of Multivariate Statistical Programs. Tech. Report of State University of New York at Stony Brook.

Ryther, J. H. \& W. H. Dunstan, 1971. Nitrogen, phosphorus and eutrophication in the coastal marine environment. Science, Vol. 171, pp. 1008-1013.

SoKal, R. R. \& F. J. Rohlf, 1969. Biometry. W. H. Freeman and Co., San Francisco, 776 pp.

STEELE, J., 1974. The structure of marine ecosystems. Harvard University Press, Cambridge, Mass., $128 \mathrm{pp}$.

Whitney, D. E., G. M. Woodwell \& R. H. Howarth, 1975. Nitrogen fixation in Flax Pond: a Long Island salt marsh. Limnol. Oceanogr., Vol. 20, pp. 640-644.

WIEBE, P. H., 1970. Small scale spatial distribution in oceanic zooplankton. Limnol. Oceanogr., Vol. 15, pp. 205-217. 